\title{
Acidentes humanos com macacos em relação a tratamentos profiláticos para a raiva, no Município de São Paulo, Brasil
}

\author{
Human accidents with monkeys in relation to prophylactic treatment \\ for rabies, in the Municipal district of São Paulo, Brazil
}

\author{
Pedro Melguizo Ramos ${ }^{1}$ e Pedro Silva Ramos ${ }^{2}$
}

\begin{abstract}
Resumo Apesar do Município de São Paulo apresentar a raiva sob controle epidemiológico ( último caso de raiva em humanos foi registrado em 1981) e de 95,4\% de sua população residir na área urbana, se registram casos de acidentes humanos envolvendo animais silvestres e dentre estes, os macacos estão envolvidos no maior número de casos. No período de 1996 a 1999 foram atendidas 69.967 pessoas vítimas de acidentes com animais, das quais 267 acidentes com macacos. Neste trabalho se estuda a incidência mensal e anual da ocorrência destes acidentes, bem como os tratamentos antirábicos realizados.
\end{abstract}

Palavras-chaves: Acidentes com macacos. Raiva. Tratamentos anti-rábicos.

\begin{abstract}
Although the Municipal District of São Paulo has rabies under epidemic control (last case of rabies in humans was registered in 1981) and 95.4\% of its population resides within the urban area, there are reports of human accidents involving wild animals and of these, monkeys are involved in the largest number of cases. In the period from 1996 to 1999, 69,967 victims of accidents with animals were attended, of which 267 were accidents with monkeys. In this work the monthly and annual incidence of the occurrence of such accidents was studied, as well as the antirabies treatment provided.
\end{abstract}

Key-words: Accidents with monkeys. Rabies. Antirabies treatment.

Os macacos são reservatórios de inúmeras zoonoses, entre as quais a raiva, doença mortal: após o aparecimento dos sintomas não existe tratamento'.

Pessoas agredidas por animais mamíferos, devem ser submetidas a tratamento anti-rábico pós exposição: vacinação ou sorovacinação, dependendo da gravidade e local da lesão. A dispensa deste tipo de tratamento só ocorre quando o animal agressor é sacrificado e o exame por imunoflorescência direta do célebro for negativo. Somente para cães e gatos é possível a dispensa de tratamento quando após 10 dias de observação clinica, contados a partir da data do acidente, se apresentarem sadios $^{3812}$.
No mundo, nos países em desenvolvimento, o principal transmissor da raiva é o cão e nos países desenvolvidos, os transmissores são os animais silvestres ${ }^{13}$.

No Brasil, foram notificados 873 casos de raiva em humanos, na década de 1980 a 1989, dos quais 4 $(0,5 \%)$ casos foram transmitidos por macacos; no período de 1990 a 1999 se registrou uma significativa queda na incidência de raiva em humanos com 408 casos, dos quais o macaco foi o transmissor em 9 $(2,2 \%)$ casos. O macaco é a quarta espécie transmissora da raiva a humanos, sendo superada apenas pelos cães, morcegos e gatos ${ }^{4}$.

\footnotetext{
1. Programa de Prevenção da Raiva em Humanos, da Secretaria Municipal de Saúde de São Paulo, São Paulo, SP. 2. Médico Veterinário autônomo. Endereço para correspondência: Dr. Pedro Melguizo Ramos. Centro de Controle de Zoonozes. R. Santa Eulália 86, 02031-020 São Paulo, SP. Tel: 11 6221-9755, Fax: 11 6221-9823.

Recebido para publicação em 21/2/2002.
} 
No Município de São Paulo, cujo último caso autócne de raiva em humanos ocorreu em 1981, não há registro de transmissão de raiva por essa espécie, mas é importante a vigilância desses acidentes para que tal fato não venha a ocorrer ${ }^{5}{ }^{10}$. As principiais espécies agressoras são o cão (88\%), o gato $(6,2 \%)$ e os ratos $(4,7 \%)^{6}$. Os acidentes envolvendo macacos ocorrem em parques públicos, quando pessoas inadvertidamente oferecem alimentos aos mesmos, ou em residências situadas em áreas de matas que são invadidas por esses animais a procura de alimentos ou no meio urbano por pessoas que os mantém clandestinamente em suas casas como mascotes.

As espécies mais comuns nesses acidentes são o Cebus sp (macaco prego) e Callithix sp (sagui).
O Município de São Paulo, com uma população de 10.434.252 habitantes (IBGE - Censo de 2000) ${ }^{2}$, é um dos maiores aglomerados urbanos do mundo. Com uma área de 1.509 quilômetros quadrados, a região urbana representa $65,6 \%\left(990 \mathrm{Km}^{2}\right)$ e nela residem $95,4 \%$ de sua população (9.813.187 habitantes) ${ }^{11}$. Apresenta regiões de mata atlântica, com animais silvestres: ao norte a Serra da Cantareira, com residências de alto nível em terrenos de $1.000 \mathrm{~m}^{2}$, em média e ao sul a Serra do Mar com casas construídas em loteamentos clandestinos, em áreas de preservação ambiental. O índice pluviométrico médio, no período de 1996 a 1999 foi de 1381 milímetros/ano, distribuídos $51,3 \%$ no verão (janeiro a março), 11,3\% no outono (abril a junho), $12,1 \%$ no inverno (julho a setembro) e $25,3 \%$ na primavera (outubro a dezembro).

\section{MATERIAL E MÉTODOS}

No Município de São Paulo, a Secretaria Municipal de Saúde instituiu o Programa de Prevenção da Raiva em Humanos ${ }^{9}$ e atualmente 12 Unidades Médicas (Hospitais e Pronto Socorros) atendem às vítimas deste tipo de acidentes e realizam o tratamento, quando indicado.

Para cada atendimento, é preenchida uma ficha epidemiológica específica denominada Ficha de investigação de acidentes com animais, onde são anotados data do acidente, espécie animal envolvida, local da agressão, possível causa do acidente, indicação ou não de tratamento, etc e que serve para o acompanhamento do caso (abandono, interrupção médica, convocação ao abandono, reações adversas, etc).

Foram separadas as fichas de acidentes com macacos, ocorridos no período em estudo e agrupadas mensalmente.

\section{RESULTADOS}

No período de 1 de janeiro de 1996 a 31 de dezembro de 1999, foram notificados 69.967 acidentes humanos com animais, dos quais 267 acidentes com macacos, o que representou um índice médio de 0,4\%.

Destes acidentes, em 227 vítimas foi indicado o tratamento anti-rábico (soro vacinação) ou seja uma taxa media de $85 \%$ de indicação de tratamento.

$\mathrm{Na}$ Tabela 1, são relacionados anualmente estes acidentes e os tratamentos antirábicos indicados.

A incidência deste tipo de acidentes não foi uniforme ao longo dos meses do ano: os meses de maior incidência, no período em estudo, foram os meses de agosto com $11,2 \%$ dos casos, seguidos de julho e fevereiro com $10,5 \%$ cada um; os meses de menor incidência foram os de novembro com $4,1 \%$ dos casos e abril com 5,2\% ( Tabela 2 ).

Com relação aos acidentes, de acordo com as estações do ano, observou-se:

$$
\begin{aligned}
& \text { verão }=79(29,6 \%) \\
& \text { outono }=56(21,0 \%) \\
& \text { inverno }=79(29,6 \%) \\
& \text { primavera }=53(19,8 \%)
\end{aligned}
$$

\section{DISCUSSÃO}

A baixa (0,4\%), porcentagem de acidentes humanos com macacos quando comparados com outros animais (cães e gatos) no Município de São Paulo deve-se ao fato de sua grande urbanização. Mas deve-se considerar que os custos com estes tratamentos são elevados, o tratamento quando indicado consiste sempre em sorovacinação: soro $(40 \mathrm{UI} / \mathrm{Kg})$ mais 13 doses de vacina (1 dose diariamente, em 10 dias consecutivos e 3 doses de reforço $=10,20$ e 30 dias após a administração da $10^{3}$ dose).

Para se ter uma idéia, no período em estudo, nos 227 tratamentos indicados foram utilizadas 2.951 doses de vacina; deve-se destacar que $40 \%$ das vítimas são crianças de até 12 anos de idade e estas necessitam do acompanhamento de um adulto à Unidade Médica para a administração da vacina ${ }^{7}$; portanto foram perdidos 4.131 dias para as vítimas e para a sociedade, devendo-se levar em conta ainda o sofrimento psíquico e emocional diante do medo de contrair a raiva.

Observa-se uma diminuição dos acidentes humanos com macacos em números absolutos, percentualmente quando comparados ao total de acidentes humanos envolvendo animais verifica-se uma redução de $50 \%$ de 1996 para os demais anos em estudo, nos quais estes índices se mantém constante em $0,3 \%$.

Este fato, provavelmente, deve-se a maior conscientização das pessoas quanto à criação clandestina desses animais e quanto a não alimentação dos mesmos em parques públicos. 
Tabela 1 - Total de acidentes com animais, com macacos e tratamentos indicados, no Município de São Paulo, 1996 a 1999

\begin{tabular}{|c|c|c|c|c|c|}
\hline \multirow[b]{3}{*}{ Ano } & \multirow{3}{*}{$\begin{array}{c}\text { Acidentes } \\
\text { com animais } \\
\text { total }\end{array}$} & \multicolumn{4}{|c|}{ Macacos } \\
\hline & & \multicolumn{2}{|c|}{ acidentes } & \multicolumn{2}{|c|}{ tratamentos } \\
\hline & & $\mathrm{n}$ - & $\%$ & $\mathrm{n}^{\circ}$ & $\%$ \\
\hline 1996 & 15.195 & 108 & 0,7 & 85 & 78,7 \\
\hline 1997 & 19.235 & 59 & 0,3 & 51 & 86,4 \\
\hline 1998 & 18.840 & 57 & 0,3 & 49 & 86,0 \\
\hline 1999 & 16.697 & 43 & 0,3 & 42 & 97,7 \\
\hline Total & 69.967 & 267 & 0,4 & 227 & 85,0 \\
\hline
\end{tabular}

Tabela 2 - Incidência mensal de acidentes humanos com macacos no Município de São Paulo, no período de 1996 a 1999.

\begin{tabular}{lccccc}
\hline Mês & 1996 & 1997 & 1998 & 1999 & Total \\
\hline janeiro & 8 & 7 & 5 & 5 & 25 \\
fevereiro & 4 & 9 & 11 & 4 & 28 \\
março & 11 & 5 & 5 & 5 & 26 \\
abril & 8 & 1 & 4 & 1 & 14 \\
maio & 8 & 4 & 5 & 2 & 19 \\
junho & 14 & 1 & 3 & 5 & 23 \\
julho & 16 & 7 & 3 & 2 & 28 \\
agôsto & 9 & 5 & 8 & 8 & 30 \\
setembro & 10 & 4 & 6 & 1 & 21 \\
outubro & 11 & 4 & 4 & 4 & 23 \\
novembro & 4 & 4 & 0 & 3 & 11 \\
dezembro & 5 & 8 & 3 & 3 & 19 \\
\hline Total & 108 & 59 & 57 & 43 & 267
\end{tabular}

De outro lado, verifica-se um aumento das taxas de indicação de tratamento, sendo que em 1999 apenas em um dos acidentes ocorreu a dispensa de tratamento anti-rábico.
Com relação às estações do ano, observa-se um aumento desses acidentes no verão e inverno de cerca de $10 \%$ como ocorre nas estações anteriores, primavera e outono.

\section{REFERÊNCIAS BIBLIOGRÁFICAS}

1. Acha PN, Szyfres B. Zoonosis y enfermedades transmissibles comunes al hombre y a los animales. Organization Panamericana de la Salud. $2^{\text {th }}$ edition, Washington, p. 502-526, 1986.

2. Instituto Brasileiro de Geografia e Estatística. População. www.ibge.gov.br/ibge/estatistica/população. 2002.

3. Ministério da Saúde. Centro Nacional de Epidemiologia. Coordenação de Controle de Zoonoses e Animais Peçonhentos. Norma técnica de tratamento profilático anti-rábico humano. $2^{\mathrm{a}}$ edição, Brasília, 1995.

4. Ministério da Saúde. Centro Nacional de Epidemiologia. Coordenação de Controle de Zoonoses e Animais Peçonhentos. Relatórios da Coordenadoria de Zoonoses e Animais Peçonhentos. Brasília. 1980 a 1999.

5. Ramos PM. O controle da raiva no Município de São Paulo. Revista do Conselho Federal de Medicina Veterinária - Suplemento Técnico, Brasília/DF, no 19 , p. 46-50, janeiro a abril de 2.000 .

6. Ramos PM, Ramos PS. Estudo retrospectivo quanto aos animais agressores para a raiva no Município de São Paulo, no período de 1988 a 1997. Revista de Educação Continuada do Conselho Regional de Medicina Veterinária de São Paulo 2 : 81-84, 1999.
7. Ramos PM, Ramos PS. A importância do "Programa de Controle da raiva" implantado no Município de São Paulo, Brasil: aspectos econômicos e de saúde pública. Revista de Educação Continuada do Conselho Regional de Medicina Veterinária de São Paulo, 2: 85-88,1999.

8. Secretaria Municipal de Saúde. Norma técnica de profilaxia da raiva em humanos. Diário Oficial do Município, 16 de setembro de 1994.

9. Secretaria Municipal de Saúde. Programa de prevenção da raiva em humanos. Diário Oficial do Município, 9 de junho de 1994.

10. Secretaria Municipal de Saúde. Boletins Informativos do Controle de Zoonoses Urbanas. São Paulo 1984 a 1997.

11. Secretaria Municipal de Planejamento. Guia de Serviços Públicos Cidade de São Paulo, p. 14, 1998.

12. Secretaria do Estado de Saúde. Profilaxia da Raiva em Humanos. Manual Técnico nํ 4. Instituto Pasteur, São Paulo, 1999.

13. Word Health Organization. Department of Communicable Disease Surveillance and Response. World Survey of Rabies, 1998, Geneve, nㅇ 34, p. 16, 2000. 